ARtigos 


\title{
PERCEPÇÕES DO TEMPO E TRABALHO: AS DISPUTAS DOS SERTANEJOS POBRES NO EXTREMO NORTE DE GOIÁS EM TORNO DOS SEUS MODOS DE VIVER - 1860 A 1920
}

Olivia M. M. Cormineiro*

\begin{abstract}
Resumo: Este artigo investiga as disputas sobre o tempo entre sertanejos pobres e demais grupos sociais no extremo norte de Goiás entre as décadas de 1860 e 1920. Inspirado na História Social, compreendida em seu sentido mais amplo como um campo de relações e lutas de classes, busca problematizar a tensão entre os modos costumeiros de conceber e "viver o tempo" dos sertanejos pobres, as práticas de dominação dos fazendeiros locais e as políticas de disciplinarização do trabalho promovida pela província/estado de Goiás. Ao trilhar este caminho a investigação apontou que nesta região, ao menos até a década de 1930, manteve-se certa integração entre vida e trabalho, apesar de, já desde fins do século XIX, vir esta articulação entre tempos diversos sofrendo forte pressão.
\end{abstract}

Palavras-chaves: trabalho, tempo, cultura.

Abstract: This article investigates the arguments on the time between poor-from the backwoods and too many social groups in the northern extreme of Goiás between the decades of 1860 and 1920 . When the tension was inspired in the Social History understood in his most spacious sense as a field of relations and class struggles, search problematizar between the customary ways of conceiving and "to survive the time" of the poor backwoodsmen, the practices of domination of the local farmers and the politics of disciplinarização of the work promoted by the province / state of Goiás. While treading this way to investigation it pointed what in this region, at least up to the decade of 1930, maintained certain integration between life and work, in spite of, already from ends of the century XIX, this articulation came between different times suffering strong pressure.

Keywords: work, time, culture.

O objetivo deste artigo é investigar as disputas vinculadas às percepções do tempo nas relações de trabalho entre sertanejos pobres, fazendeiros e Estado no extremo norte de Goiás entre as décadas de 1860 e 1920. De fato, compreender como o tempo era representado e como era vivido contribui para, a partir do desvelamento de um campo de possibilidades, evidenciar as formas como se configuravam nos circuitos das políticas de disciplinarização do trabalho e do mandonismo a tensão em torno das práticas de trabalho dos sertanejos pobres.

Nesse sentido é importante ressaltar que a proposta deste artigo é pensar a tensão em torno das percepções de tempo nas relações de trabalho sertanejas entre pessoas livres desde antes da emancipação dos escravos. Silvia Hunold Lara nos alerta no artigo "Escravidão, cidadania e história do trabalho no Brasil" para o risco de assumirmos o ano de

\footnotetext{
* Mestranda do Programa de Pós-graduação em História Social da Universidade Federal de Uberlândia - UFU. Bolsista CAPES. Vinculada à Linha de Pesquisa Trabalho e Movimentos Sociais. Contato: oliviacormineiro@uol.com.br
} 
1888 como um marco temporal que separa duas formas diametralmente opostas de relações: o trabalho escravo e o livre. Segundo Hunold, "a maior parte dos autores que tratam da história do trabalho no Brasil costuma iniciar sua análise no final do século XIX ou mesmo nas primeiras décadas do século $\mathrm{XX}^{\prime \prime} .{ }^{1} \mathrm{O}$ interesse de Hunold no artigo acima referido é questionar a exclusão do trabalhador escravo das análises sobre trabalho, porém seus questionamentos nos permitem problematizar outras dimensões como, por exemplo, alguns cânones da História do Trabalho. Acompanhando esta perspectiva, interessa mais de perto a este artigo problematizar especialmente que sob o marco de 1888 estão subsumidos não apenas o escravo como um trabalhador, mas também o trabalhador livre antes da emancipação.

Em outras palavras, se o trabalhador escravo é opacizado na história do trabalho, o trabalhador livre que viveu antes de 1888 , principalmente nas regiões mais afastadas do "litoral", também o é. De fato, foi consolidado pela historiografia que após 1888 ocorreu um período de transição da escravidão para o mercado de trabalho livre, ficando-nos a impressão que trabalhadores livres e escravos não existiram fora do marco estabelecido para sua aparição na historiografia. Não é esta a perspectiva assumida neste artigo. Aqui procuramos pensar este jogo de relações observando que desde antes da emancipação os trabalhadores livres e pobres, aqui denominados sertanejos pobres, empreendiam estratégias que não significavam nada menos que modos de luta contra a exploração.

É necessário reconhecer que não estamos analisando aqui as percepções de tempo e trabalho de "operários", que desde antes do início do século XX buscavam organizar uma luta contra a dominação e a exploração. O trabalhador sertanejo pobre exercia uma variedade de atividades de forma muito irregular e as evidências não nos permite distribuílos neste período e região por categorias profissionais. Por outro lado, a irregularidade e multiplicidade não excluíam determinada coadunação em torno de atividades mais específicas. Assim, a atividade primordial do sertanejo pobre era o cultivo da terra, ou seja, eram lavradores, porém nos intervalos desta atividade, ou concomitantemente, era também caçador, pescador, apanhador de castanhas, arrieiro ${ }^{2}$, quebrador de coco babaçu, piloto de

\footnotetext{
${ }^{1}$ HUNOLD, Silvia L. Escravidão, cidadania e história do trabalho no Brasil. Projeto História: Revista do Programa de Estudos Pós-graduados em História e do Departamento de História da PUC-SP, n. 16, São Paulo: Educ., 1998, p. 26.

${ }^{2}$ Segundo Moura Lima, literato e estudioso da linguagem regional, arrieiro eram os sertanejos pobres que trabalhavam ajustados como camaradas com a função de tomar conta dos animais de carga, das cargas e de
} 
bote $^{3}$, peão do eito ${ }^{4}$, remeiro ${ }^{5}$, extrator de caucho (borracha). No campo ou nas povoações, estas atividades eram realizadas pelos sertanejos pobres em regimes de camaradagem ${ }^{6}$, jornal $^{7}$ e agregação ${ }^{8}$, o que caracteriza que sua identificação neste artigo passa pelo reconhecimento nestes sujeitos do partilhamento de experiências de exploração, dominação, negociação e resistência que os define, ainda que sem nenhuma rígida determinação, como pessoas pobres que viviam do trabalho e que habitavam o sertão ${ }^{9}$ de Goiás, no período já especificado.

todos os materiais necessários e levados durante as viagens, comerciais ou não, por rota terrestre no sertão do extremo norte de Goiás. MOURA, Lima, Chão de Carabinas: coronéis, peões e boiadas. Gurupi: Cometa, 2002.

${ }^{3}$ Conforme Couto de Magalhães em Viagem ao Araguaia botes são grande embarcações, nos moldes de uma canoa, movida a remos, que fazia o transporte de pessoas e produtos pelos rios do sertão do extremo norte de Goiás. COUTO DE MAGALHÃES, J. V. Viagem ao Araguaia. 7ạ Edição, São Paulo: Ed. Três, 1974.

${ }^{4}$ Peão do eito, conforme Hugo de Carvalho Ramos em Tropas e Boiadas, era o sertanejo-pobre que se ajustava como camarada para realizar qualquer tarefa, conhecido na região como o "faz tudo" ou homem da enxada, do machado, da foice, etc. RAMOS, H. C. Tropas e Boiadas. 8a Edição, Goiânia: Editora UFG, 1998.

${ }^{5}$ Conforme Couto de Magalhães, em Viagem ao Araguaia, remeiros eram os sertanejos pobres que se ajustavam como camaradas para, remando, colocarem os botes em movimento em viagens que chegavam a durar seis meses. COUTO DE MAGALHÃES, J. V. Viagem ao Araguaia. 7ạ Edição, São Paulo: Ed. Três, 1974.

${ }^{6}$ Segundo Ana Lúcia da Silva, camaradagem era o contrato verbal de trabalho assumido por qualquer trabalhador "que fizesse um ajuste de trabalho com outrem para prestação de serviços na lavoura, pecuária, empreitadas de viagens e serviços domésticos". SILVA, A. L. A revolução de 30 em Goiás. Goiânia: Cânone. 2001, p. 40-41.

${ }^{7}$ Jornal no extremo norte de Goiás, entre as décadas de 1860 e 1930, é o trabalho realizado pelos sertanejos pobres por diárias, não possuindo um vínculo contratual ou costumeiro com seu empregador.

${ }^{8}$ Apesar de existirem inúmeras compreensões para o termo agregação, utilizo aqui a forma cunhada por Auguste de Saint-Hilaire entre 1818 e 1819: agregação era uma forma de relação em que "indivíduos que nada possuem de seu se estabelecem em terreno de outrem", recebendo um pedaço de terra para trabalhar em troca de certas prestações de serviço de natureza, principalmente, não econômica. Não podemos esquecer que, como qualquer outra definição, não se deve tomá-la como algo dado, mas como uma noção a ser testada frente às evidências, o que no caso específico tratado aqui significa perceber que existem múltiplas formas de agregação. SAINT-HILAIRE, Auguste. Viagem à Província de Goiás. Belo Horizonte: Editora Itatiaia, 1975, p. 64

${ }^{9}$ Sertão, em sua dimensão empírica e conceitual, é uma discussão polêmica. Entretanto, no que concerne à proposta aqui sustentada, compreendo-o como um espaço delimitado e diverso que, não obstante as dificuldades em apreendê-lo, pode ser caracterizado por sua relacionalidade. Assim, se o sertão se definia, em uma perspectiva clássica desta discussão, por sua oposição ao litoral, aqui ele se define em relação ao litoral. Acredito que o avanço é que não mais prevalece uma idéia de inferioridade, mas de tensão entre diferentes e desiguais. Neste caso, as próprias relações constituídas nos sertões, (no plural mesmo, porque não há apenas um sertão), pressupõem reconhecer que a construção dos sentidos sobre o que é o sertão e quem são os sertanejos é feita agora em bases dialógicas e, especialmente, sob a intervenção dos sujeitos sociais determinados que vivem e/ou viveram nestes espaços delimitados. Sobre sertão ver FREITAS DE JESUS, A.L. O sertão e sua historicidade: versões e representações para o cotidiano sertanejo - séculos XVIII e XIX. Revista História e Perspectiva. UFU. Uberlândia, 35, 2o semestre de 2006, p. 247. 


\section{Os Modos de Viver o Tempo dos SeRTANejos Pobres}

Considerando os apontamentos realizados acima, faz-se necessário esclarecer que as disputas sobre o tempo são parte de um conflito mais amplo: o conflito em torno do modo de vida do sertanejo pobre no interior de uma determinada cultura sertaneja, que no período aqui estudado sofria constantemente as pressões de um projeto civilizador que tinha como principal objetivo disciplinar o trabalhador. Não obstante, como veremos adiante, as pressões externas - disciplinarização, controle social etc. - só adquirem sentido para a análise da tensão em torno dos modos de viver dos sertanejos pobres, tanto quanto para a própria vivência dos grupos sociais no sertão, se considerarmos que as relações internas no extremo norte de Goiás, no período aqui analisado, foi o lugar social onde pressões e limitações foram vividas e que são nestas relações que as transformações e continuidades podem ser percebidas e compreendidas. Assim, mesmo reconhecendo que o capitalismo tem a tendência geral de reproduzir-se e ampliar-se, considero pertinente o alerta de Élio Garcia Duarte de que quando "se analisa sua expansão [do capitalismo] em regiões de economia predominantemente rural, é preciso levar em consideração algumas peculiaridades como o poder dos resíduos do passado, as tradições culturais locais e a força política das classes ligadas a uma economia agrária". ${ }^{10}$

Nesse sentido, uma questão essencial é compreender que sob amplo aspecto os modos de trabalhar do sertanejo pobre, no âmbito das tradições e da cultura regional, se integravam à natureza. Estas pessoas, especialmente até o fim da década de 1890, construíram suas práticas de trabalho observando os ritmos naturais, assim:

nos meses de verão, turmas de sertanejos deixam os trabalhos da roça e vão acampar semanas inteiras [...] É lá que se reúnem em montes os pirarucus arpoados durante o dia, para, em seguida, retalhar, salgar, secar ao sol em estaleiros e, finalmente, enfardar os produtos da interessante pescaria. Só a carestia do sal impede, geralmente, os ribeirinhos de intensificarem a pesca do pirarucu. ${ }^{11}$

\footnotetext{
${ }^{10}$ DUARTE, Élio Garcia. Apresentação. In: BORGES, B. G. Goiás nos Quadros da Economia Nacional. Goiânia: Editora UFG, 2000, p. 6.

${ }^{11}$ AUDRIN, Frei José Maria. Os sertanejos que eu conheci. Rio de Janeiro: Livraria José Olympio Editora, 1963, p. 32.
} 
Podemos perceber analisando a narrativa acima que o sertanejo pobre construiu seus modos de trabalhar mediante uma notação muito específica acerca da distribuição das tarefas no transcorrer do tempo. Assim, do trabalho na roça, especialmente entre os meses de maio a outubro, o lavrador passa à pesca do pirarucu nos meses de dezembro a abril, ou à caça da lontra e da ariranha. Thompson, analisando a questão do tempo e da disciplina de trabalho no século XVIII na Inglaterra, afirma haver uma inter-relação entre trabalho e natureza no que se refere

ao condicionamento essencial em diferentes notações de tempo geradas por diferentes situações de trabalho, e suas relações com os ritmos "naturais". É óbvio que os caçadores devem aproveitar certas horas da noite para colocar as suas armadilhas. Os pescadores devem integrar as suas vidas com as marés [...] A notação de tempo que surge nesses contextos tem sido descrita como orientação pelas tarefas. ${ }^{12}$

É provável que o sertanejo pobre estivesse observando a prescrição natural como um elemento limitador, certamente pelas implicações que os ritmos naturais neste período e local impunham. Entretanto, é necessário lembrar que, para além das limitações naturais, as atividades venatórias eram importantes atividades econômicas no extremo norte de Goiás, pois, como afirma Ana Lúcia Silva, as peles silvestres e a carne salgada do peixe pirarucu representavam produtos importantes de exportação entre as décadas de 1850 e 1930 em Goiás. ${ }^{13}$

Não obstante, não podemos negar que as formas pelas quais os sertanejos pobres organizavam suas vidas diferenciava-se dos modos prescritos pela sociedade capitalista européia. O historiador José Carlos Barreiro busca compreender em seu trabalho Imaginário e viajantes no Brasil do século XIX ${ }^{14}$ quais concepções de tempo e trabalho permeavam os relatos dos viajantes estrangeiros que estiveram no Brasil durante o século XIX. Observa este historiador que os viajantes não compreendiam que para os "grupos subalternos" as noções de tempo vinculadas ao trabalho disciplinado não tinha significado dentro dos seus modos de viver. Barreiro aponta que os viajantes ao descreverem os ritmos de trabalho das pessoas pobres nos locais onde passavam enfatizavam quase sempre seu caráter de ócio e

12 THOMPSON, E. P. Costumes em Comum: estudos sobre cultura popular tradicional. Trad. Rosaura Eichemberg. São Paulo: Companhia das Letras, 1998, p. 271.

${ }^{13}$ SILVA, A. L. A revolução de 30 em Goiás. Goiânia: Cânone, 2001.

${ }^{14}$ BARREIRO, J. C. Imaginário e viajantes no Brasil do século XIX: cultura e cotidiano, tradição e resistência. São Paulo: Editora UNESP, 2002. 
indolência. Problematizando tal questão, Barreiro nos adverte para o fato de que entre os trabalhadores pobres do século XIX as concepções de tempo e trabalho da sociedade européia não estavam ainda consolidadas.

Também o historiador Nasr Fayad Chaul, analisando a formação da sociedade goiana, preocupa-se em desconstruir as idéias de atraso, decadência e indolência utilizadas por viajantes e cronistas do século XIX para descreverem a Província de Goiás. Segundo Chaul, os viajantes edificaram a idéia de que

a precariedade das estradas e as poucas existentes isolavam Goiás, a carência das comunicações isolava o comércio (Pohl), a incapacidade do povo em se superar o isolava (D'Alincourt). As casas abandonadas nos arraiais, para onde o povo ia apenas em ocasião das festas religiosas (Saint-Hilaire) eram o retrato do sertão de Goiás. Rural e sem produção agrícola, rico em ouro e pobre em alimentos, carente em tudo e sem forças para sair do marasmo (Cunha Mattos e Taunay). Reino do ócio e da preguiça $[. . .]^{15}$

Acompanhando as reflexões de Chaul e Barreiro, questionamos as visões constituídas sobre as relações sociais no extremo norte de Goiás e defendemos que os padrões integrativos de tempo e trabalho ultrapassavam os modos de viver dos pobres do sertão, vinculando-se, de forma mais ou menos identificável, aos modos de viver dos grupos dominantes - políticos e/ou econômicos - do extremo norte de Goiás ao menos até a década de 1890. Em outras palavras, os sertanejos pobres não viviam sozinhos neste espaço e partilhavam com os demais grupos de sertanejos - compostos por fazendeiros, coronéis, grandes posseiros e autoridades - determinada flexibilização no uso do tempo. O próprio instituto escravista, seguindo este caminho, foi um elemento estabilizador da cultura sertaneja: uma dimensão da vida destes sertanejos - pobres ou ricos -, cuja função era manter a flexibilidade do uso do tempo nas atividades de trabalhar e viver dos homens livres.

O escravo exercia nesta cultura o papel central de ampliador do tempo e de intensificador máximo do trabalho, liberando, guardadas as devidas ressalvas que não será possível desenvolver aqui, a população livre para manter-se sob critérios mais integrativos de vida e trabalho. Assim, senhores de escravos - fazendeiros que em regra tinham o mando da terra - posseiros, agregados e roceiros partilhavam, culturalmente, as notações de tempo

${ }^{15}$ CHAUL, N. F. Caminhos de Goiás: da construção da decadência aos limites da modernidade. Goiânia: Ed. UFG, Ed. UCG, 1995, p. 42. 
neste sertão. Acompanhando esta perspectiva, Couto de Magalhães, ainda na década de 1880, esclarece que: “a caça e a pesca [...] para o norte [de Goiás] exprimem um exercício indispensável à existência, pois dela depende considerável parte dos gêneros com que se alimentam as famílias do interior, sejam elas ricas ou pobres". ${ }^{16}$

Obviamente, estou ciente da complexidade da proposição de Couto de Magalhães. Em primeiro lugar, porque uma alimentação análoga podia significar apenas uma imposição dos meios naturais à subsistência dos sujeitos que habitavam um espaço comum, não significando um partilhamento cultural. Por outro lado, nesta realidade histórica determinada não podemos deixar de considerar que partilhar a alimentação em um espaço onde adquirir pela compra não era uma possibilidade constante, ou até mesmo inconstante, coloca tais sujeitos partilhando não apenas a alimentação, mas as formas de consegui-la, ou seja, partilhando modos de trabalhar, inclusive com a perspectiva de associações inevitáveis.

\section{O TEMPO DISCIPLINADO: FAZENDEIROS E SERTANEJOS POBRES EM UMA RESISTÊNCIA PARTILHADA}

Observando o caminho trilhado até agora, estou propondo ser imprescindível para se entender as notações de tempo dos sertanejos pobres no extremo norte de Goiás perceber que as formas de compreender e viver a relação tempo e trabalho eram aspectos partilhados por ricos e pobres - ao menos até o início do século XX - dentro da cultura sertaneja. Thompson, analisando a questão do costume dos trabalhadores ingleses no século XVIII, chama atenção para dois aspectos sobre o tratamento da cultura. O primeiro é a tendência clássica a preterir os aspectos culturais e privilegiar as áreas econômicas das relações sociais. O segundo aspecto é, quando se trata do problema cultural, "a invocação confortável de um consenso, [...] distrai nossa atenção das contradições sociais [...], das fraturas e oposições existentes dentro do conjunto". ${ }^{17}$

Antonio Gramsci discute nos Cadernos do Cárcere $^{18}$ a questão da cultura em sua compreensão hegemônica, apontando especificamente como nas experiências materiais,

\footnotetext{
${ }^{16}$ COUTO DE MAGALHÃES, J. V. Viagem ao Araguaia. 7ạ Edição, São Paulo: Ed. Três, 1974, p. 34

${ }^{17}$ THOMPSON, E. P. op. cit., p. 17, 21.

${ }^{18}$ GRAMSCl, Antonio. "Americanismo e Fordismo". Cadernos do cárcere. v. 4. Trad. Carlos Nelson Coutinho. Rio de Janeiro: Civilização Brasileira, 2001, p. 239-283.
} 
concretas e historicamente determinadas, necessidades e interesses são disputados no interior de uma determinada cultura. Ou seja, mesmo no interior de uma cultura dominante, cujo poder é exercido por determinado grupo, a cultura se constitui em espaço de tensão e lócus de resistência, tanto quanto de subordinação. Assim a compreensão que temos aqui de partilhamento cultural das notações de tempo entre grupos dominantes e sertanejos pobres não opaciza ou desconsidera a disputa pela concretização da exploração/dominação ou da autonomia. Novamente é José Carlos Barreiro quem nos provoca ao problematizar que o "conceito de hegemonia tem servido freqüentemente para veicular a idéia de dominação absoluta dos governantes sobre os governados. Este tipo de interpretação obscurece a percepção da sociedade a partir da luta de classes, incorporando a idéia de que os subalternos absorvem as representações burguesas de forma linear" ${ }^{19}$

Assim, no que se refere à cultura sertaneja do extremo norte de Goiás é necessário perceber a dominação econômica e política que fazendeiros e posseiros exerciam sobre os sertanejos pobres, porém no interior desta cultura dominação e subordinação eram experimentados como práticas sociais que não nos permitem compreender como as relações de forças se configuravam senão dentro das lutas de classes. Ou seja, a cultura sertaneja, da qual o sertanejo pobre participava e cuja direção se encontrava em poder dos fazendeiros e posseiros, somente pode ser compreendida considerando-se que esta "tem de ser renovada continuamente, recriada, defendida e modificada. Também sofre resistência continuada, limitada, alterada, desafiada por pressões que não são suas próprias pressões". 20

Nesse sentido, é preciso atentar para a questão de que as formas de praticar e viver a dominação e a subordinação são complexas. Ademais não é simples perceber de quem e para quem as relações de poder são vividas. De fato, uma cultura não é um sistema fechado e tão pouco uma cultura de dominação pode ser compreendida fora das situações de tensão e contradição das realidades sociais. ${ }^{21}$ Nesse sentido, embora o problema do hegemônico seja bem mais amplo dentro da cultura sertaneja, para os fins que se propõe este artigo nos preocupamos justamente com os limites, as pressões e as resistências em torno das

\footnotetext{
${ }^{19}$ BARREIRO, J. C. Tradição e protesto popular no Brasil - 1780-1880. Revista Projeto História. São Paulo: Educ., n. 16, 1998, p. 12.

${ }^{20}$ WILLIAMS, Raymond. Marxismo e Literatura. Trad. Waltensir Dutra. Rio de Janeiro: Zahar, 1979, p. 115.

${ }^{21}$ GRAMSCl, Antonio. Apontamentos e notas esparsas para um conjunto de ensaios sobre a história dos intelectuais. Tradução Paolo Nosella. História e Perspectivas. Uberlândia: EDUFU, n. 5, p. 125 -165, 1991.
} 
notações de tempo, especialmente porque este problema é parte indissociável das experiências materiais concretas neste sertão.

De fato, o tempo para o sertanejo pobre tanto quanto para fazendeiros e grandes posseiros era uma dimensão constitutiva do espaço, ou seja, era vivido como prática e determinado por um lócus. Assim, medir o tempo para estes sertanejos não significava padronizar, em termos de horas e dias, as atividades, mas produzir, ao menos relativamente, um equilíbrio entre os espaços temporais de cada tarefa. Nesse sentido, o tempo vivido na roça seria a própria prática de trabalhar na lavoura, assim como o tempo da pescaria não era medido em horas, mas dimensionado pela própria prática e não pela quantidade de tempo destinado à realização da pesca. A compreensão pelos sertanejos pobres de como o tempo deveria ser vivido na realização do trabalho, como também nas atividades de lazer e devoção, parece ter determinada continuidade em relação à mesma compreensão por parte de fazendeiros e grandes posseiros. De fato, a reclamação da falta de braços feita em 1881 no Relatório de Leite Moraes, presidente de Goiás, denuncia a flexibilidade temporal como um elemento comum a ricos e pobres da região:

Ao atravessarmos qualquer fazenda, aqui e alli, por toda parte, encontramos pequenas e miseráveis choupanas - são os aggregados [...] chegai, a qualquer hora do dia, n'uma destas choupanas e ahi encontrareis o homem entregue à ociosidade [...] Não ofereçam os fazendeiros aos vagabundos guarida em suas terras, e muitos teremos conseguido. ${ }^{22}$

É improvável que os sertanejos pobres que viviam agregados às terras de algum fazendeiro vivessem entregues à ociosidade, pois conforme ressalta Carmo Bernardes, ao compor o enredo do romance Perpetinha, os fazendeiros "mantinham sua gente empregada", seus agregados "botavam rocinhas, brocados nos capões de mato, longe da praga das capivaras [...] aprumavam mutirão, faziam farinha de mandioca braba". ${ }^{23}$ Ora, embora Bernardes trate de obra de ficção, a construção de seu romance é mediada por uma larga experiência em arquivos e por sua própria vivência. Ademais, cotejando Bernardes com as memórias de Frei José Maria Audrin faz-se necessário reconhecer que, de fato, a labuta do sertanejo pobre era constituída de forma irregular, porém aos momentos menos extenuantes combinavam-se períodos de atividades intensas, pois quando na lavoura "tal

\footnotetext{
${ }^{22}$ LEITE MORAES, J. A. Relatório da Presidência da Província de Goiás. Goiânia: Typografia Goiana. 1882, p. 54.

${ }^{23}$ BERNARDES, Carmo, Perpetinha, um drama nos babaçuais. Goiânia: CEGRAF/UFG. 1991, p. 69
} 
[era] a tarefa pesada do roceiro de maio a setembro [e] ao chegarem os prenúncios das chuvas invernais trata[va]-se do plantio". ${ }^{24}$ Seguramente os sertanejos pobres não viviam na ociosidade.

De toda forma o que parece estar em jogo no posicionamento defendido no Relatório da Presidência de Goiás era, além de outras questões que fogem aos objetivos deste artigo, a adesão ou não de sertanejos pobres e fazendeiros aos projetos de organização de uma mão-de-obra. Não obstante, esta não era uma questão fundada na harmonia entre fazendeiros e pobres, tratando-se antes do fato de que a maioria dos fazendeiros, os que possuíam agregados em suas terras é claro, eram "donos de criatórios com gado" 25 o que reduzia a necessidade de braços a um ou dois vaqueiros, liberando os outros moradores da terra para conduzirem suas vidas conforme o costume, ou seja, na sua integração costumeira entre trabalho e vida.

Porém é inevitável perguntar por que estes fazendeiros, ou posseiros, manteriam famílias agregadas à sua terra? Uma das razões é a possibilidade que manter tais agregações daria aos donos da terra de comandar a vida dos homens e, como ocorria comumente, alcançar poder político. Nestes casos, não havia incompatibilidade imediata entre o tratamento do tempo, dentro desta cultura, e os objetivos políticos dos grupos dominantes. Nesse sentido, entre fazendeiros e sertanejos pobres ocorria uma espécie de troca: pelo "direito" de usar e morar na terra este último subordinava-se ao controle do primeiro. É certo que este era um acordo precário, pois a qualquer momento ou por uma razão qualquer o fazendeiro poderia expulsar o sertanejo pobre das terras onde este residia.

Por outro lado, nas últimas décadas do século XIX são visíveis os avanços da política de disciplinarização do trabalho do sertanejo pobre. Estas investidas vinham especialmente da parte do Estado, produzindo, porém, uma ampla tensão em torno da estruturação e, conseqüentemente, da desestruturação da cultura sertaneja no decorrer das três primeiras décadas do século XX. A escola e a lei foram as principais instituições de convencimento/ coerção contra as formas de compreender e viver o tempo que integravam vida e trabalho.

A primeira conseqüência destas tentativas de disciplinarização do trabalho do sertanejo pobre foi aumentar a tensão entre a classe dominante no extremo norte de Goiás - representada principalmente pelos fazendeiros que desempenhavam as funções de juízes,

\footnotetext{
${ }^{24}$ AUDRIN, Frei José Maria. op. cit., p. 47.

${ }^{25}$ BERNARDES, Carmo. op. cit., p. 69
} 
delegados e coletores de impostos - e os sertanejos pobres. Assumindo estas funções os fazendeiros representavam não apenas a classe dominante como também a classe dirigente, vinculados e dependentes da administração provincial e/ou estadual de Goiás que era a principal patrocinadora desta nova disciplina. De fato, os fazendeiros que participavam da direção do sertão sofreram, desde a década de 1890, grande pressão no sentido de reforçar as limitações às práticas integradoras de vida e trabalho, visando em primeira instância disciplinar a forma de trabalhar do sertanejo pobre.

José Vieira Couto de Magalhães, em 1889, expôs a necessidade da especialização produtiva e, conseqüentemente, da disciplinarização do trabalho, defendendo que o “aperfeiçoamento [da] indústria agrícola [seria] resultante da divisão do trabalho" ${ }^{26}$ Para alcançar o aperfeiçoamento produtivo Couto de Magalhães defendia que os roceiros se especializassem em apenas uma atividade e acabassem com o hábito de seguir "a rotina de seus pais e avôs" e buscassem se aperfeiçoar. ${ }^{27}$ Apresentando em seguida um exemplo representativo:

\footnotetext{
Supondo-se dois ferreiros, dos quais um trabalhe constantemente nas diversas obras de seu ofício, e outro que se tenha exclusivamente empregado em fazer cravos; acontecerá que este último fará 200 cravos no mesmo tempo em que o primeiro só poderá obter 100 . Tudo mais segue esta proporção, de modo que a perícia, resultante das indústrias exclusivas, traz um aumento de $50 \%$ na produção. $^{28}$
}

Couto de Magalhães retira o exemplo acima de Adam Smith, em As Riquezas das Nações, para reforçar sua idéia de que é necessário realizar a divisão do trabalho, única forma de se alcançar o necessário desenvolvimento da agricultura e pecuária no norte de Goiás, pois, nos termos propostos ainda por Adam Smith, "em toda sociedade desenvolvida, o agricultor geralmente é somente agricultor" e se dedica ao "emprego exclusivo de um gênero só de agricultura". Ora, mas para que o 'desenvolvimento agrícola' ocorresse seria preciso haver uma mão-de-obra disciplinada, pronta a realizar apenas uma atividade e realizá-la incessantemente.

Analisando o que Audrin propõe sobre os modos de trabalhar do sertanejo pobre poderemos avançar nesta discussão, porém antes se faz necessário refletir como a memória

\footnotetext{
${ }^{26}$ COUTO DE MAGALHÃES, J. V. op. cit., p. 56.

${ }^{27}$ Ibid., p. 56-57.

${ }^{28}$ Ibid., p. 57.
} 
de Frei Audrin sobre o sertanejo pobre foi construída, ainda que nos limite deste artigo não seja possível aprofundar a questão. Audrin, em determinado momento de sua narrativa, corrobora como dimensão necessária da vida do sertanejo pobre a integração entre trabalho e lazer, ou melhor, entre trabalho e vida, afirmando que

nos meses de verão, turmas de sertanejos deixam os trabalhos da roça e vão acampar semanas inteiras [...] É lá que se reúnem em montes os pirarucus arpoados durante o dia, para, em seguida, retalhar, salgar, secar ao sol em estaleiros e, finalmente, enfardar os produtos da interessante pescaria. ${ }^{29}$

Por outro lado, em outro momento afirma que o sertanejo pobre não reconhecia o valor do tempo. Acredito que a análise deste problema deva ser iniciada com a reflexão sobre o sentido da palavra valor na narrativa de Audrin. Este afirma que os sertanejos pobres não reconheciam o valor do tempo em uma situação específica: a despreocupação destes com as distâncias a serem percorridas em uma viagem, chegando a afirmar que as "mais longínquas se tornam para muitos as mais apreciadas". ${ }^{30}$ Para Audrin o sertanejo pobre era descuidado em relação ao tempo, sendo que seria "esse descuido uma das causas da 'fome velha' doença crônica em certos recantos do sertão, doença consentida, imperdoável, que tantos experimentam, mas não procuram cortar" ${ }^{31}$, ou seja, estaria atribuindo à indolência do sertanejo pobre suas condições precárias de vida. Encontramos aqui uma crítica velada, que está presente em todo o seu texto, ao fato do sertanejo pobre ainda não ter adquirido "amor ao trabalho". ${ }^{32}$ Assim, valor em Audrin significa valor do tempo enquanto trabalho. Por outro lado, aponta que uma tenacidade se revela

\begin{abstract}
no roceiro ao manejar o machado ou a enxada, desde o nascer até o pôr do sol. Sem camisa, vestido com o simples 'gongó' (calças curtas), agüenta o calor tórrido, o chuvisco teimoso, o fumaceiro sufocante das coivaras, a fome e a sede, sem falar das ferroadas dos mosquitos, piuns, carrapatos, mucuins, formigas-de-fogo, lagartas, etc. Luta tenaz que, cada ano, se prolonga durante semanas inteiras, ao tratar-se das plantações. ${ }^{33}$
\end{abstract}

Surge aqui um paradoxo em Audrin que podemos formular da seguinte maneira: Audrin considerava o sertanejo pobre um indolente, preguiçoso que não aproveitaria o

\footnotetext{
${ }^{29}$ AUDRIN, Frei José Maria. op. cit., p. 32.

${ }^{30}$ Ibid., p. 128.

${ }^{31}$ Ibid., p. 108.

${ }^{32}$ Cf. WEBER, Max. "O ascetismo e o espírito do capitalismo". In: A ética protestante e o espírito do capitalismo. São Paulo: Martim Claret, 2003.

${ }^{33}$ AUDRIN, Frei José Maria. op. cit., p. 107.
} 
tempo? Ou o considerava um sujeito que trabalha tenazmente, porém sob um ritmo diferente?

Sob minha interpretação, na narrativa de Audrin articulam-se e sobrepõem-se duas memórias. Uma constituída a partir de sua experiência junto aos sertanejos pobres, entre os anos de 1904 e 1938, e outra que surge na década de 1960, quando a obra Os sertanejos que eu conheci foi escrita. A memória construída durante o tempo em que viveu no sertão compreende ser o sertanejo pobre um trabalhador tenaz, porém reconhece também que seu trabalho era alternado entre um ritmo extenuante e um ritmo mais atenuado.

Nesse sentido, a quem Audrin estaria considerando indolente? Acredito que indolente para Audrin era o sertanejo pobre que não estando envolvido em qualquer trabalho - no roçado, na caça ou na pesca - que lhe preenchesse o tempo, não se dispusesse a empregar-se como camarada, ou seja, a vender sua força de trabalho. Assim, a idéia de valor do tempo para Audrin se esclarece: o valor do tempo com o qual os sertanejos não se preocupavam era o valor do tempo de trabalho, mas um tempo de trabalho demarcado: o tempo que se tornaria valor por meio da venda da força de trabalho.

Em Audrin, a memória que emerge quando chega à conclusão de que vagabundo seria o sertanejo pobre que não se empregasse é a memória construída a partir de seu presente, ou seja, seriam suas lembranças do sertão reelaboradas a partir de suas experiências do presente, as demandas da década de 1960 quando a narrativa foi escrita, que definiriam sua outra interpretação sobre os sertanejos pobres. Acompanhando esta perspectiva, evidencia-se que este jogo de memórias deve ser pensado também em relação há um tempo específico. Que tempo é este? A contemporaneidade de Frei Audrin. Nesse sentido, mesmo reconhecendo que as práticas de trabalho dos sertanejos pobres eram extenuantes, apesar de irregulares, é perceptível haver um conflito em sua narrativa entre esta percepção e as demandas da sociedade industrial brasileira da década de 1950 e 1960. Qual demanda seria esta? Mão-de-obra disciplinada e disposta a vender sua força de trabalho.

Portanto, valor do tempo em Audrin assume o sentido atribuído por Thompson ao tempo transmutado em dinheiro, transmutação esta que ocorreria quando a força de trabalho deixasse de ser propriedade dos trabalhadores e passasse a ser de domínio de outrem. Nesse tipo de trabalho, segundo Thompson, "o que predomina não é a tarefa, mas 
o valor do tempo quando reduzido a dinheiro. O tempo é agora moeda: ninguém passa o tempo e sim o gasta". ${ }^{34}$

Entretanto, os sertanejos pobres não estavam dispostos a abrir mão das especificidades de suas vidas, ou seja, resistiam a aceitar que suas vidas se tornassem unidimensionais e que suas práticas de trabalho fossem alijadas de seus modos de viver. Principalmente, resistiam a vender sua força de trabalho, pois o ônus imediato seria a vigilância do patrão, a submissão aos seus olhos e o controle direto de seu tempo. Assim, um dos principais empecilhos para que o sertanejo pobre aceitasse empregar-se como camarada era o problema do controle direto. No trabalho de apanhador de castanhas, por exemplo, o controle do tempo do sertanejo pobre era tão amplo que somente lhes era permitido caçar aos domingos e era estritamente proibido cuidar de qualquer cultivo durante os meses da safra de castanhas, comumente durante o período das chuvas.

De fato, as caçadas nas florestas de castanha eram feitas "ordinariamente aos sábados e domingos" quando os sertanejos pobres, algumas vezes, conseguiam autorização. Nas sociedades contemporâneas onde as caçadas são pensadas quase sempre apenas como lazer é fácil entender que somente os fins de semana fossem destinados a esta atividade. Entretanto, para o sertanejo pobre a situação era muito mais complexa e não se tratava apenas da questão do controle, pois este sujeito estava sendo impedido também de prover seu sustento, o que torna a afirmação de Ignácio Batista de Moura, em 1896, de que os apanhadores de castanhas são uma "massa [...] perseguida pelas febres intermitentes [...] mal [se] abrigando em palhoças provisórias contra as chuvas abundantes, e alimentando-se insuficiente." ${ }^{35}$ Mas esta questão não é tão simples: a adesão à venda da sua força de trabalho nunca, ou quase nunca, era voluntária, porém em grande medida era negociável.

Realmente, entre as décadas 1890 e 1920, a maior arena de disputa social no mundo sertanejo foi a adesão, ou não, ao contrato formal de trabalho, instituído pela Lei de Camaradagem $^{36}$, que previa para os sertanejos pobres regras desintegradoras de seus modos de viver. Os artigos desta lei mais penosos, e em função dos quais os sertanejos

\footnotetext{
${ }^{34}$ THOMPSON, E. P. op. cit., p. 272.

${ }^{35}$ MOURA, I. B. De Belém a S. João do Araguaia: Vale do Rio Tocantins. Belém: CEJUP, 1989, p. 153.

${ }^{36}$ Lei no. II de 20 de julho de 1892. Esta lei versava sobre a venda da força de trabalho dos pobres e baseava-se, ao menos formalmente, no reconhecimento da cessão mão-de-obra como relação de trabalho assalariado, porém, nas realidades concretas, representava antes a tentativa de legitimar, após o fim do estatuto escravista, a exploração máxima do trabalhador livre. Arquivo Público de Goiânia Cx. 04.
} 
pobres mais resistiam a locar sua força de trabalho, eram os que prescreviam ter o camarada a obrigação de residir no local de trabalho. Nos Capítulos II, III e V estava inscrito:

Art. 20 - O locador que se obrigar a prestar serviços na lavoura, deve residir no estabelecimento em que tenha de trabalhar, salvo a permissão do locatário para dormir fora [...] Art. 28 - O locador que se dedicar aos serviços de criação de gado de qualquer espécie, também é obrigado, salvo combinação em contrário, a residir no estabelecimento em que se empregar [...] Art. 42 - Qualquer pessoa de um ou outro sexo, que se ajustar com outra para prestar-lhe serviços domésticos, como cozinhar, lavar, engomar, etc., é obrigado a residir em casa do locatário, da qual não poderá ausentar-se sem uma permissão, e ahi deverá pernoitar, salvo convenção em contrário. ${ }^{37}$

Na condição de camarada, o tempo de viver do sertanejo pobre passava para o domínio do patrão, principalmente porque na referida Lei de Camaradagem estava previsto no Capítulo VI, das penalidades, em seu artigo 44 que "incorrerá na pena de 10 a 20 dias de prisão: 1ㅇ - O locador que se ausentar sem motivo justo; 2으- O que permanecendo no estabelecimento, não quizer trabalhar". ${ }^{38}$ Obviamente os patrões não mandavam seus camaradas para a prisão por toda e qualquer ausência, porém às vezes alguns eram levados presos, o que, por um lado, coibia as ausências mais sistemáticas dos que estivessem com seus serviços locados. Entretanto, por outro lado, contribuía para que a resistência a esta forma de trabalhar aumentasse entre os que não estivessem com os seus serviços locados.

A Primeira República foi, de fato, uma arena de disputas sangrentas em torno das políticas de organização do trabalho no extremo norte de Goiás. Em primeiro lugar, porque, como afirma Emília Viotti da Costa, a mudança de regime político em 1889, apesar das permanentes e renovadas pressões em torno da organização do trabalho assalariado, não significou um rompimento das estruturas políticas que sob muitos e importantes aspectos buscavam reproduzir formas costumeiras de organização social do trabalho. ${ }^{39}$ Assim, o próprio grupo dominante no extremo norte de Goiás discordava em muitas questões do governo goiano, tanto quanto discordavam entre si, no que se refere ao problema da organização de mão-de-obra.

Desde 1892, ano da publicação da Lei de Camaradagem, a oligarquia comandada por Leopoldo de Bulhões dominou o cenário estadual em Goiás, atingindo, inclusive,

\footnotetext{
${ }^{37}$ Lei N.ㅇl de 20 de julho de 1892. Lei de Camaradagem. Arquivo Público de Goiânia Cx. 04.

38 Ibid.

${ }^{39}$ COSTA, Emília Viotti da. Da Monarquia à República: momentos decisivos. 6ạ ed. São Paulo: Editora UNESP, 1998.
} 
projeção nacional até fins da primeira década do século XX. A organização administrativa bulhonista em Goiás integrava-se totalmente à política coronelista e, segundo Itami Campos:

Mesmo não possuindo terras, os Bulhões tornaram-se porta-vozes nacionais de Goiás e defensores dos interesses da pecuária e dos demais setores da economia regional. Mantiveram o princípio da carta-branca às lideranças locais, satisfazendo exigências e não interferindo nos negócios municipais, além de, em termos de política fiscal, não sobrecarregarem os produtos agropecuários, nem a posse da terra. $^{40}$

A política de não-interferência dos Bulhões conseguiu estabelecer um relativo equilíbrio em Goiás até mais ou menos 1903. Porém, desde 1902 a política praticada pelo Governador José Xavier de Almeida, que inicialmente era um aliado do Senador Leopoldo de Bulhões, modificou-se. Xavier de Almeida em mensagem enviada ao Congresso assim expôs seus objetivos quanto a Goiás:

Exercer a mais severa vigilância na arrecadação e dispêndio dos dinheiros públicos; [...] As grandes fronteiras do Estado, a falta de vias férreas ou de uma navegação fluvial regularmente organizada e a antiga práctica de condescendências, a que se habituaram exactores e contribuintes, constituem sérias dificuldades para um governo que, antes de tudo, deseja a fiel e rigorosa observância das leis e seus regulamentos. $^{41}$

O conteúdo da mensagem acima não representava simples exercício de retórica. A política fiscal proposta por Xavier de Almeida foi mantida por seus sucessores o que infalivelmente levou ao rompimento com os bulhonistas, surgindo a partir de então em Goiás uma ruptura partidária. Esta ruptura, em termos práticos não representaria uma grande cisão política não fosse por dois aspectos: a dura fiscalização tributária dos Xavieristas e suas fortes e marcadas relações com a família Caiado.

O primeiro aspecto culmina com o Movimento de 1909, quando coronéis e fazendeiros argumentando que a vitória nas eleições em Goiás do grupo Xavieristas se devia a fraudes, mas na verdade preocupados com o aperto fiscal, arregimentaram "seus homens" e seguiram para a capital de Goiás com o objetivo de impedir a posse de Hermenegildo Lopes de Moraes, um aliado de Xavier Almeida. Uma questão precisa ser levantada: o fator de ambigüidade e muitas vezes de contradição entre as políticas estaduais e os interesses regionais e locais de coronéis e fazendeiros. Observemos que durante o período bulhonista

\footnotetext{
${ }^{40}$ CAMPOS, Itami. Coronelismo em Goiás. 2ạ ed. Goiânia: Editora Vieira, 2003, p. 84.

${ }^{41}$ Mensagem ao Congresso, 1902, p. 4-40.
} 
foi colocada em vigor a Lei de Camaradagem que pretendia obrigar os sertanejos pobres a trabalhar sob contrato, porém quase nunca assalariado, ao mesmo tempo em que buscava coibir um tipo específico de agregação: a que se caracterizava pela possibilidade do sertanejo pobre morar na terra controlada por algum fazendeiro sem nenhuma obrigação material ou de trabalho.

Não podemos negar que até certo ponto a demanda por mão-de-obra era interesse dos coronéis, porém não lhes interessava colocar fim ao regime de agregação, pois eram estes homens que em momentos estratégicos, como no movimento de 1909 contra as pressões fiscais do grupo Xavierista, empunhavam armas e defendiam suas posições. Assim, muitas vezes, tanto os grupos dirigentes, que com menos dificuldade aderiram à normalização do tempo nas relações de trabalho, quanto os fazendeiros que eram oposição no extremo norte de Goiás costumavam ora opor franca resistência a estas novas condições de trabalho, ora 'faziam-se de surdos' continuando a viver o tempo conforme o costume, o que reforçava em muitas ocasiões as estratégias de resistência dos sertanejos pobres.

A socióloga Ana Lúcia da Silva aponta que a fonte de poder das elites rurais em Goiás no final do século XIX encontrava-se no fato de os fazendeiros controlarem o circuito do capital. Assim, para Silva, era "com base neste poder econômico, [que] os coronéis projetavam seu poder a todos os níveis do poder político, elegendo para as câmaras e para a presidência do Estado seus parentes, seus aliados, seus apaniguados, seus protegidos" . ${ }^{42} \mathrm{Se}$ compararmos as condições materiais de existência dos sertanejos pobres ao poder econômico dos fazendeiros facilmente poderíamos afirmar que toda a determinação das relações sociais no sertão se encontra na questão produtiva, porém o que quero ressaltar aqui é que o poder no extremo norte de Goiás, neste período específico, não se restringia ao problema econômico. Aliás, acredito que reduzir a questão de poder no extremo norte à questão das relações de produção é negligenciar aspectos importantes das relações sociais.

O que me preocupa é a articulação entre o propriamente econômico e a dimensão cultural nas relações de poder no extremo norte de Goiás, especialmente no que se refere à relação tempo e trabalho. Seguramente, nem sempre os sertanejos pobres tinham sua mãode-obra diretamente explorada, muitos viviam e trabalhavam sem se fazerem camaradas, ou seja, utilizavam sua força de trabalho e de sua família para produzirem seu sustento por

\footnotetext{
${ }^{42}$ SILVA, A. L. op. cit., p. 43.
} 
conta própria e em benefício próprio. Estes sertanejos pobres eram comumente agregados e não respondiam, enquanto mão-de-obra, aos fazendeiros e grandes posseiros da região o que the permitia organizar seu tempo conforme os interesses de sua vida, embora em algumas formas de agregação a exploração fosse intensa. Por outro lado, e talvez o mais importante, mesmo não respondendo como mão-de-obra, em função de uma organização cultural específica da sociedade sertaneja, respondiam como subordinados políticos, ou seja, mesmo com a exploração mitigada eram dominados, pois os fazendeiros controlavam as terras onde estes agregados viviam e, conseqüentemente, comandavam os homens.

$\mathrm{Na}$ relação entre poucos proprietários, alguns posseiros e muitos agregados havia um campo cultural comum que se traduzia na forma de uma reciprocidade desigual, ou seja, dentro da cultura sertaneja havia algum consenso sobre o fato de que entre vida e trabalho era necessário haver integração e que o tempo era o elemento mediador. Assim, mesmo os sertanejos pobres agregados à posse ou propriedade de algum fazendeiro possuíam, como apontado acima, alguma liberalidade para trabalhar conforme suas expectativas de viver, porém, esta liberalidade poderia ser suspensa a qualquer momento em função dos interesses do fazendeiro.

Nesse sentido, mesmo com a possibilidade de manter seus modos de viver integrados, os sertanejos pobres muitas vezes eram obrigados a romper suas atividades costumeiras em função das demandas dos fazendeiros e chefes políticos da região. Nestes casos específicos, a disputa não residia na questão da exploração do trabalho, mas no enfrentamento da questão do comando da terra. Ora, o "comandar a terra" não se referia a tornar a terra produtiva, mas a comandar o homem, que era da terra, e torná-lo parte da engrenagem política do sertão. Foi o que ocorreu em 1909, os sertanejos pobres agregados às fazendas sob o comando dos coronéis marcharam para a capital de Goiás para defender os interesses de "seus patrões", porém também para defender a dimensão integrativa de tempo e trabalho em seus modos de viver.

Os desdobramentos do Movimento de 1909 são muitos e complexos, porém o principal foi a constituição de dois blocos políticos em Goiás. A queda dos Xavieristas, ao contrário do que muitos coronéis esperavam, não representou um fortalecimento dos Bulhões, mas o surgimento de outro bloco na política coronelista de Goiás: o da família Caiado. Fato este que conjugado às disputas locais e regionais intensas iniciou um período de revoltas e lutas armadas no norte de Goiás que perdurou até a década de 1930. Neste 
contexto, temos nos eventos ocorridos a partir de 1910 em Pedro Afonso um exemplo da complexidade das relações e das lutas travadas por e contra interesses das facções coronelísticas em Goiás.

Nos conflitos de Pedro Afonso havia ao menos três lados que de forma alguma eram fixos ou estáveis. De um lado, por exemplo, havia Abílio Araújo, um 'mandão', que perseguido por crimes cometidos em Santa Rita, cidade do interior da Bahia, instalou-se em Piabanhas, povoado pertencente a Pedro Afonso. Conforme Othon Maranhão ${ }^{43}$, Abílio trouxe consigo dez homens que empregou na extração da borracha, principal produto econômico da região neste período, porém ele trouxe também o medo. Por um lado, os ricos temiam a proeminência econômica que Abílio vinha alcançando com o negócio da borracha, por outro lado o sertanejo pobre estava amedrontado com as notícias das vendetas em que aquele havia se envolvido na Bahia.

Em função disto, os chefes políticos de Pedro Afonso na perspectiva de terem seus domínios invadidos começaram a armar-se contra Abílio Araújo. Contra este se formaram dois grupos: um ligado aos Bulhões e outro, sob a liderança de Coronel Eugênio Jardim, vinculado aos Caiados. Ou seja, na pequena cidade do extremo norte goiano as disputas estaduais articulando-se aos interesses das elites locais, mas também aos interesses dos sertanejos pobres, construíram significados que extrapolava qualquer sentido simplificado de coronelismo. Estes dois grupos arregimentaram pessoas para realizar rondas na cidade de Pedro Afonso, o que além de aumentar a tensão entre si, terminou por levar a própria população a formar um terceiro grupo, liderado por um sertanejo pobre, contra Abílio Araújo. Muitos acontecimentos desenrolaram-se no decorrer deste conflito, porém a razão para descrever como se configurou em termos de grupos esta luta é registrar que o momento não admitia neutralidade.

E a adesão dos sertanejos pobres certamente foi requerida. Moura Lima ao buscar representar em seus romances como os sertanejos pobres viviam a violência afirma que cada grupo "na calada da noite, promov[ia] uma reunião secreta. E ali, no cochicho de rosário [...] manda[vam] chamar a caboclada do sertão [...]". ${ }^{44}$ A representação literária de Moura Lima consegue expressar uma dimensão importante do viver das pessoas pobres no

\footnotetext{
${ }^{43}$ MARANHÃO, Othon. Setentrião Goiano. 2ae ed. Goiânia: Centro Gráfico do Senado Federal, 1990.

${ }^{44}$ LIMA, Moura. Serra dos Pilões. Jagunços e Tropeiros - Romance nos sertões do Jalapão. 3a ed. Gurupi: Cometa, 2001, p. 76.
} 
sertão, pois ao narrar o "mandar chamar a caboclada" estaria indo ao cerne da questão da dominação, especialmente do agregado que é mandado chamar de longe, onde vive nas terras de coronéis e fazendeiros. Cotejando Moura Lima com algumas memórias sobre os momentos de maior conflito no extremo norte é possível perceber que este romancista consegue plasmar em seus romances a dimensão mais humana desta dominação que é o "mandar chamar na calada da noite", ou seja, a qualquer hora o sertanejo pobre deveria estar preparado para atender ao chamamento do coronel.

De fato, os caboclos de que fala Moura Lima não eram outros senão os sertanejos pobres, que se viam obrigados a atender as ordens dos "chefes da terra" ou ao chamamento da sobrevivência, não porque todos trabalhassem para os fazendeiros ou para os grupos dominantes, mas porque dependiam socialmente, primordialmente nestes momentos de crise, de algum dos lados. Estes sertanejos pobres nestas "alianças inevitáveis" alteravam sua relação com suas roças, suas caçadas e pescadas, suas festas e encontros, ou seja, seu envolvimento nas disputas políticas representava muitas vezes o abandono de seus interesses. Assim, retornando ao exemplo acima, tanto os dez trabalhadores da borracha, homens trazidos por Abílio Araújo, quanto os caboclos que tinham sido recrutados para salvar a cidade de Pedro Afonso tinham sua relação com o tempo construída essencialmente sob uma irregularidade.

Irregularidade esta que em situações extremas tornava a vida bastante difícil, pois os sertanejos pobres, "na sua maioria, [por] tomarem parte na revolução, obrigados por uma parte ou por outra parte, [deixavam] a lavoura abandonada". ${ }^{45}$ Não obstante, é preciso esclarecer que o envolvimento destas pessoas nas disputas políticas, apesar das imposições dos fazendeiros e coronéis, não era apenas uma questão de dominação. Os sertanejos pobres nestas circunstâncias, mesmo em condições desiguais, buscavam atender suas necessidades e interesses. Assim, quando arregimentados por qualquer dos lados para as lutas ou quando espontaneamente engajavam-se, o que não era raro apesar de menos comum, empreendiam uma série diversa de estratégias com o objetivo de "compensar" a desarticulação do seu tempo de viver.

No conflito na cidade de Boa Vista, em 1908, encontramos exemplos das estratégias dos sertanejos pobres em defesa de seus interesses durantes as revoltas políticas no

${ }^{45}$ DUARTE L. G. De são Vicente a Araguatins. Cem anos de fundação - 1868 -1968. Goiânia: J. C. Rocha, 1970, p. 28. 
extremo norte de Goiás. Nesta cidade, desde 1900, dividiam o poder político o Padre João Lima e a família Moreira, cujo principal representante era Leão Leda, porém um dos desdobramentos da ascensão política de Xavier de Almeida foi o surgimento de um desequilíbrio no poder nesta cidade. Assim, se durante o controle bulhonista em Goiás a política local e regional eram exercidas sem muita interferência, durante o governo de Xavier de Almeida e Rocha Lima as configurações mudaram. Segundo o historiador Luiz Palacín, o governador Rocha Lima, a partir de 1906, "inclinou-se decididamente do lado dos Moreiras, o que levou à eclosão da segunda revolução de Boa Vista." ${ }^{46}$

Esta revolta em Boa Vista repercutiu em São Vicente do Araguaia, além de em outras povoações, atingindo os sertanejos pobres. Conforme diversos relatos, "com a retirada dos chefes que aqui estiveram mais de dois meses ficou a povoação [São Vicente] entregue à sanha desenfreada dos capangas que cometiam depredações e abigiatos ${ }^{47}$ [...]". ${ }^{48}$ A fala acima é de Duarte um comerciante de São Vicente, que rememorando a história desta povoação afirma que após a retirada dos líderes da revolta, São Vicente ficou entregue à ação de capangas. No entanto, logo a seguir este mesmo Duarte diz que os sertanejos, pobres lavradores, eram o braço armado dos revoltosos, pois foram em sua maioria "obrigados" a aderirem a qualquer dos lados.

Ora, compreendo que, conforme o próprio Duarte expõe, os capangas eram em grande parte os lavradores arregimentados, porém Duarte somente se refere aos capangas como lavradores, quando, no retorno das autoridades à povoação, perceberam que o abastecimento alimentar estava comprometido. De toda forma, pretendo ressaltar que estes sertanejos pobres, neste momento específico e neste local, aproveitaram a retirada dos chefes e saquearam estabelecimentos, roubaram gado e outras coisas, e fizeram isso porque sabiam que não havia na povoação qualquer autoridade que thes pudesse coibir, pois todos haviam fugido para o Pará ou Maranhão.

Analisando a questão acima percebo que apesar de exploração e dominação estarem presentes cotidianamente na vida dos sertanejos pobres, estes algumas vezes empreendiam, dentro de seus campos de possibilidades, meios de não perderem

\footnotetext{
${ }^{46}$ PALACIN, L. G. Coronelismo no extremo norte de Goiás: O Padre João e as Três Revoluções de Boa Vista. São Paulo: Edições Loyola. 1990, p. 121.

${ }^{47}$ Abigiato significa roubo de gado, porém ao cotejar várias fontes verifiquei que esta palavra aparece especialmente nas memórias para significar qualquer tipo de roubo.

${ }^{48}$ DUARTE L. G. op. cit., p. 28. [Grifo nosso].
} 
completamente o controle de suas vidas. Fosse por meios de medidas pensadas, fosse por meio da irrupção do crime e da violência, estes homens, mulheres e crianças estavam lutando por seus modos de viver que, no que se refere à relação entre tempo e trabalho, se expressava pelo desejo de manter seu tempo sob seu controle. Nesse sentido, a violência, a depredação e o roubo não representavam apenas uma vingança contra seus opressores, apesar de não podermos negligenciar o significado desta apropriação para o próprio sertanejo pobre em termos materiais, mas uma busca por retomar, ainda que por algumas horas ou dias, sua autonomia.

Por outro lado, em grande parte do tempo, ao menos até a década de 1930, os sertanejos pobres conseguiram manter minimamente uma integração entre seu tempo e sua vida, porém por esta época o conflito em torno desta questão era permanente e já apareciam indícios de que os sertanejos pobres haviam perdido esta batalha. Afinal, o trabalho disciplinado era uma prioridade do Estado Novo em maior intensidade e abrangência do que no tempo da República Velha, o que pode ser visto com clareza no Decreto N. $411^{49}$ do Interventor de Goiás publicado no "Correio Oficial" em 30 de dezembro de 1930, que reafirma com algumas alterações ${ }^{50}$ a Lei de Camaradagem de 1892, mas esta já é outra história.

\section{CONSIDERAÇÕES FINAIS}

Considero que a própria dinâmica social no extremo norte de Goiás por esta época fortalecia a irregularidade na realização do trabalho, tanto quanto de todas as atividades dos sertanejos pobres, o que em certo sentido permitia que uma resistência à desintegração de seus modos de viver persistisse. Os sertanejos pobres ao disputar sobre o tempo, lutavam pelo direito de escolher suas vidas e, dentro de suas possibilidades, disputavam também por oportunidades de atenuar a exploração de sua força de trabalho.

\footnotetext{
${ }^{49}$ SILVA, A. L. op. cit.

${ }^{50}$ A principal inovação deste Decreto, em relação à Lei de Camaradagem de 1892, é a presença de uma tabela salarial, porém como sabemos do que consta na lei ao que é vivido, na maioria das vezes, há uma longa distância.
} 
Assim, me parece que havia a percepção por parte destes sujeitos que aderir às lutas locais, neste caso não importando quem vencesse, possibilitaria a continuidade de alguns padrões costumeiros, pois as próprias lutas eram parte destes padrões. De fato, a exploração dentro da sociedade sertaneja, apesar dos conflitos permanentes entre sertanejos pobres e fazendeiros, mantinha-se sob um terreno comum, que os contratos de trabalho, o recrutamento, a escola obrigatória, interpretadas pelos sertanejos pobres como modernidades da capital, insistiam em desarticular. Efetivamente, é necessário reconhecer, que neste período, as notações de tempo integrativas de trabalho e vida foram sendo desarticuladas, porém é também necessário compreender que esta desarticulação se deu lentamente.

Mais importante ainda, é entender que esta desintegração, concluída talvez somente a partir da década de 1960, representou não somente transformações quanto ao tempo, mas, principalmente, transformações nos modos de viver dos sertanejos. Nesta perspectiva, compreender como o sertanejo pobre vivia o tempo é um problema fulcral não porque estas pessoas tenham pensando sobre o tempo, mas porque é na articulação entre tempo e espaço que se torna possível perceber a dinâmica, constituída de tensões e limitações, das disputas sociais. É este movimento, está relação entre sujeitos com interesses e necessidades diversos que faz da reflexão sobre o mundo sertanejo no extremo norte de Goiás, entre as décadas de 1860 e 1920, uma questão essencial, pois permite que percebamos a mudança na vida das pessoas e a relação destas transformações com as configurações sociais na contemporaneidade. 